\title{
PERSPECTIVE
}

\section{Balancing the Rights to Protection and Participation: A Call for Expanded Access to Ethically Conducted Correctional Health Research}

\author{
Cyrus Ahalt, MPP', Craig Haney, $P h D$, JD', Stuart Kinner, $P h D^{3,4,5,6,7}$, and Brie Williams, $M D, M S^{7}$ \\ 'Department of Medicine, Division of Geriatrics, University of California, San Francisco, San Francisco, CA, USA; ${ }^{2}$ Psychology Department, University \\ of California, Santa Cruz, Santa Cruz, CA, USA; ${ }^{3}$ Centre for Adolescent Health, Murdoch Children's Research Institute, Melbourne, Australia; \\ ${ }^{4}$ Melbourne School of Population and Global Health, University of Melbourne, Parkville, Australia; ${ }^{5}$ Griffith Criminology Institute, Griffith University, \\ Nathan, Australia; ${ }^{6}$ Mater Research Institute, University of Queensland, Brisbane, Australia; ${ }^{7}$ School of Public Health and Preventive Medicine, \\ Monash University, Clayton, Australia.
}

Incarcerated individuals, over 95\% of whom are eventually released, experience high burdens of chronic disease and behavioral health and social risk factors. Understanding the health needs of this population is critical to ensuring that general medicine physicians in prisons and in the community are adequately prepared to meet those needs. However, people in prison are significantly underrepresented in health research. In response to historical exploitation of prisoners in medical experimentation, federal guidelines appropriately require additional oversight for, and limit the scope of, research in prisons. Yet, according to a 2006 Institute of Medicine report, these requirements have produced inconsistent local regulations that often limit opportunities for incarcerated individuals to participate in research, and can slow the development of innovative medical interventions to improve their health. In this article, we describe the historical context surrounding regulations on research involving individuals in prison, the harms that can arise from excessive limitations to research in such settings, and the benefits of greater access to ethically conducted research in prison. We conclude with recommended actions that can be taken by general medicine researchers, correctional leaders, and policymakers to achieve consistent access to health research for incarcerated populations.

KEY WORDS: prison; corrections; research; ethics.

J Gen Intern Med 33(5):764-8

DOI: $10.1007 / \mathrm{s} 11606-018-4318-9$

(c) Society of General Internal Medicine 2018

I ncarceration has affected tens of millions of Americans in recent decades, 1,2 particularly black and Latino men in communities with poor access to health care. ${ }^{3}$ The impact of health disparities among the incarcerated, and the quality of

Received September 15, 2017

Revised December 14, 2017

Accepted January 12, 2018

Published Online February 5, 2018 the health care they receive, extends into the community, with implications for general medicine practitioners. For example, individuals who experience incarceration have disproportionately high rates of chronic disease, mental illness, and substance use disorders, ${ }^{4,5}$ which directly affect community health systems, since over $95 \%$ of prisoners are eventually released. 6, 7 Poor health among incarcerated individuals also adversely affects the health of their families: their children, spouses, and parents. ${ }^{8,9}$ For these reasons, experts and policymakers consider mass incarceration a public health crisis. ${ }^{10,11}$ Yet people in prison are profoundly underrepresented in health research, limiting the development of evidence-based health interventions for this population. ${ }^{12,13}$

With a growing criminal justice reform movement at state and local levels, correctional health research has become even more urgent. This is because many criminal justice reform measures have an impact on health care delivery, including, for example, policies to reduce the use of incarceration in response to substance use disorders and mental illness, and others (e.g., sentencing, parole, and bail reforms) aimed at shifting large populations from correctional health care systems to the care of general medicine practitioners in community health care systems. Patients transitioning from incarceration to community settings are at high risk for adverse health outcomes, including poor chronic disease management, inadvertent discontinuation of medications for serious mental illness, substance use relapse, and death. ${ }^{14-16}$ As a result, criminal justice reforms should be informed by knowledge about the health and social needs of the incarcerated; however, that evidence is markedly underdeveloped. ${ }^{12,17,18}$

The research gap in correctional settings exists in the context of appropriately stringent safeguards protecting incarcerated people from exploitation. Following a history of degrading and harmful research in U.S. prisons, the federal government responded by classifying prisoners as a "vulnerable population" in need of additional protections in order to participate in research. ${ }^{19}$ However, the federal guidelines that followed resulted in some local regulations that restricted the right of incarcerated individuals to participate voluntarily in ethical research designed to benefit them. ${ }^{20}$ This manuscript offers 
recommendations for steps that can be taken by general medicine researchers and clinicians, correctional leaders, and policymakers to support expanded access to ethically conducted correctional health research designed to improve the health of currently and formerly incarcerated patients.

\section{BACKGROUND TO CORRECTIONAL HEALTH RESEARCH IN THE U.S.}

Stringent protections for incarcerated individuals participating in research are well-founded, rooted in a history of exploitation. $^{21}$ Following World War II, attorneys defending Nazis asserted equivalence between Nazi medical experiments on prisoners and common practice in U.S. correctional facilities. This unexpected line of defense led to an independent review of health research conducted in U.S. prisons. The results, published in the Journal of the American Medical Association, ${ }^{22}$ described dangerous drug experimentation in an Illinois state prison as "ideal," 23 establishing a low bar for ethical correctional health research.

A boom in poorly regulated, risky, and exploitative medical research with prisoners followed. ${ }^{24}$ But reform was ultimately spurred by revelations regarding the unethical Tuskegee syphilis study - conducted with 600 non-incarcerated African Americans to study the devastating effects of untreated syphilis. $^{25}$ In response, Congress established a national commission to develop guidelines for research with vulnerable subjects, including prisoners. ${ }^{26}$ Three years later, under the sponsorship of the Department of Health, Education, and Welfare (DHEW Report), the commission issued DHEW Report Publication No. 76-131, Report and Recommendations: Research Involving Prisoners (the DHEW Report). ${ }^{27}$

The DHEW Report distinguished three types of medical research being conducted with prisoners (Box 1), and raised concerns about the first, which the authors termed "biomedical research." The commission recommended that prisoners "receive a fair share of the benefits of research," and supported, with additional ethical safeguards, research designed to improve prisoners' health and/or investigate the causes and effects of incarceration. These recommendations were integrated into the 1979 Belmont Report, ultimately leading to the 1991 Federal Policy for the Protection of Human Subjects. Today, this "Common Rule" is codified into law providing ethical guidelines for research on human subjects and requiring additional protections for research involving prisoners. ${ }^{28,}$ 29

\section{Box 1 The Three Types of Research Conducted in Prisons} According to the DHEW Report Report

1. "Biomedical research" including the development of new treatments via phase 1 drug testing.

2. Research with the "intent and reasonable probability" of improving prisoner health.

3. Research investigating the causes, effects, and processes of incarceration.
Box 1. (continued)

The DHEW Report Report recommended excluding category 1 research from correctional settings. Categories 2 and 3 were used in the development of federal guidelines to describe permissible research with people in prison.

As the Common Rule emerged, researchers were also acknowledging that restrictions on research participation for specific populations could produce unintended health inequities. ${ }^{30}$ The AIDS epidemic, for example, brought renewed attention to the DHEW Report Report's "fair share of the benefits of research." 31 Politicized patients and advocates asserted their right to participate in early-stage trials for potentially lifesaving - but experimental and high-risk - drugs. ${ }^{32,33}$ Women's health advocates also argued that women were unfairly excluded from clinical trials, and successfully pressed the National Institutes of Health (NIH) to adopt new rules for the inclusion of women and minorities in research. ${ }^{34}$ Today, researchers prioritize participatory research to improve the health of vulnerable populations ${ }^{35}$ and recognize voluntary and informed participation in research as a right, even when it poses some risk to health or confidentiality. ${ }^{32}$

Federal protections for prisoners are narrow. They define "prisoners," mandate a special institutional review board composition for prisoner research, and require that correctional research potentially benefit prisoners as a class. These additional safeguards are appropriate and essential to protecting prisoners from exploitation and harm. However, additional regulations aiming to meet this higher standard of protection have proliferated in some states and institutions. These local regulations, though well-intended, can infringe on incarcerated individuals' right to voluntarily participate in research, limiting the growth and spread of knowledge needed to improve medical practice and policy for this population. ${ }^{12,13,18}$

\section{IMPLICATIONS OF STATE AND INSTITUTIONAL VARIATION IN CORRECTIONAL HEALTH RESEARCH REGULATION}

In 2006, the Institute of Medicine (IOM) issued a landmark report describing the dearth of correctional health research and calling for more research 'to facilitate prisoners' successful reentry into society... and inform policy makers about the most humane and effective strategies for the operation of correctional systems." 20 The report attributed some of the research gap to varying regulations, either in state law or Department of Corrections (DOC) policy, concluding that such "policies may preclude potential remedies ... to ensure equitable research participation by prisoners." 20

In this context, many DOCs rely on their own expertise, research infrastructure, and funding to conduct quality improvement research, adapt community-based innovative health care models to the correctional setting, and evaluate whether they are meeting their constitutional obligation to provide community standard care. Asking that DOCs alone 
perform these critical duties alongside their core responsibilities as correctional agencies may represent a conflict of interest and could produce biased results. Yet in our 2015 review of all criminal justice-related health research funding awarded by the NIH from 2008 to 2012, we reported that just 90 health research grants were awarded to projects undertaken by independent researchers in partnership with state DOCs or local jails. ${ }^{18}$ The lack of such partnerships prevents whatever knowledge is generated within DOCs from reaching physicians in the community who will ultimately care for the more than $95 \%$ of these patients who are released.

In unpublished analyses from our 2015 review, we also found that no NIH funding over this 5-year time frame was granted to research conducted in partnership with California prisons, which house nearly $10 \%$ of all U.S. prisoners. In contrast, the Rhode Island DOC, with a prison population approximately $1 \%$ of California's, partnered with outside researchers for $13 \mathrm{NIH}$ grants totaling more than $\$ 16$ million. This funding disparity reflects a significant difference in regulation between the two states. In California, correctional research is restricted by provisions of the penal code passed in 1977 following the DHEW Report Report. The code defines "biomedical research" as any "research relating to or involving biological, medical, or physical science," encompassing most if not all health research, and states that "biomedical research shall not be conducted on any prisoner in this state." Conversely, Rhode Island has no state laws limiting research with people in prison. Its DOC requires strict adherence to federal guidelines for ethical research with prisoners without imposing categorical research exclusions. Their extramural research approval policy is publically available, transparent, and streamlined. ${ }^{36}$ Rhode Island's approach has produced partnerships with independent researchers that have led, for example, to the development of correctional care models that link patients in prison to community health care upon release, and evidence-based strategies to interrupt the costly cycle of repeat incarceration for medically vulnerable populations. ${ }^{37-39}$ In the process, they have developed innovative programming to combat the opioid crisis. ${ }^{40-42}$

In an effort to expand evidence-based correctional health care in their state, California policymakers recently passed a law specifying that the ban on biomedical research in prisons does not include the use of "statistical data in the assessment of the effectiveness of non-experimental public health programs or treatment programs in which inmates routinely participate." ${ }^{43}$ This law opens up a wealth of secondary health data for researchers. However, California continues to prohibit the enrollment of individuals in clinical and outcomes research, effectively excluding patient perspectives from research and undermining efforts to improve patient-centered care for these medically vulnerable Californians. For example, California medical parole laws allow for the early release of incarcerated individuals with serious health care needs, yet such releases are rare. ${ }^{44}$ Research describing the prevalence of serious illness, advance care planning needs, and trajectories of cognitive and functional decline among incarcerated older adults could be used to help the state make better use of its existing laws. Such research would benefit California taxpayers, who bear the costs of care for incarcerated patients with serious illness that would be lower in community settings, while optimizing care for seriously ill people in prison who are not released. Such research cannot be conducted using secondary data alone.

\section{A NATIONAL REMEDY}

Protecting people in prison from exploitation and harm is critical from a medical ethics perspective. But failure to include this population in ethically conducted research designed to address the health risks that disproportionately affect them also has ethical implications. For example, a recent report by the Massachusetts state legislature found that the risk of opioid overdose death among recently incarcerated adults was 120 -fold that among the general population, and that the majority of such deaths occurred in the first month following release from jail or prison. ${ }^{45}$ Participatory research with incarcerated people is needed if community-based health practitioners are to understand and respond to the unique factors underlying this extreme disparity in behavioral health-related mortality risk. The relative lack of such research recalls the circumstances that led to the ethically motivated movement to expand access to research for people living with HIV in the early years of the AIDS epidemic. ${ }^{33}$ Today, participatory research is standard practice in the community, as patient perspectives are recognized as essential to developing efficient and effective health policies, programs, and strategies of care. Ensuring that people in prison have similar access to research should be regarded as an ethical imperative by health researchers, practitioners, and policymakers.

Consistent access to ethically conducted health research for incarcerated individuals would provide general medicine practitioners with the knowledge needed to implement evidencebased transitional care interventions and to provide effective chronic disease management, mental health care, and substance use disorder treatment to this unique, high-risk patient population. The expansion of such research could also yield measurable public benefits, including reduced recidivism, ${ }^{46}$ improved family and community health, ${ }^{47}$ and a more judicious use of public funds, ${ }^{17} \$ 12.3$ billion of which is currently spent on prison health care each year. ${ }^{48}$

There are specific steps that general medicine researchers and practitioners, correctional leaders, and policymakers could take to address the research gap in U.S. jails and prisons (Box 2). For example, researchers could engage with correctional institutions to address their research needs, correctional leaders could adapt their policies to reflect the 2006 IOM report guidelines, and policymakers could convene 
multidisciplinary stakeholder reviews of correctional research regulations. As the nation grapples with its failed experiment in mass incarceration and that experiment's complex public health legacy, ethically conducted research across our nation's many diverse systems of justice will be essential to improving the health and health-related outcomes of current and former prisoners, their families, and their communities. We should not deny willing individuals the right to participate in that effort.

\section{Box 2 Recommendations to Expand Access to Participation in} Research for Incarcerated Individuals

\footnotetext{
Health Researchers

- Engage correctional institutions and agencies to understand research needs.

- Consider incorporating criminal justice-involved individuals and/or questions about criminal justice history in current research.

- Engage individuals who are recently released from jail or prison in existing and new community-based research projects to better understand the needs of this population.

- Understand IOM guidelines for ethical research with people in prison.

Correctional Leaders

- Eliminate restrictions on ethically conducted primary research that falls within the scope of permissible research under Subpart $C$ of the federal guidelines.

- Develop a list of research priorities and areas of need for outside expertise.

- Partner with outside researchers to develop and fund quality improvement research.

- Understand IOM guidelines for ethical research with people in prison.

Policymakers

- Review existing laws and state government regulations to identity legal restrictions on incarcerated individuals' right to participate in research.

- Convene stakeholders for a policy review (e.g. health researchers, correctional leaders, affected individuals, and community members) and research agenda setting, including agencies that provide services to individuals following release from jail or prison.

- Consider administrative and legislative remedies as needed.
}

Corresponding Author: Brie Williams, MD, MS; Department of Medicine, Division of GeriatricsUniversity of California, San Francisco, San Francisco, CA, USA (e-mail: brie.williams@ucsf.edu).

Author Contributions All authors listed here meet authorship criteria, and all those who contributed to the manuscript are listed as authors.

Funding Dr. Williams, Professor Haney, and Mr. Ahalt received grant funding support from the University of California Office of the President Multicampus Research Programs and Initiatives. Dr. Williams's time is supported in part by funding from the Department of Medicine at UC San Francisco. Professor Kinner received funding support from the Australian National Health and Medical Research Council (APP1078168). The funders played no role in the design, development, analysis or preparation of this manuscript.

\section{Compliance with Ethical Standards}

Prior Presentations: This work has not been presented previously.

Conflict of Interest: Dr. Williams and Professor Haney have served as expert witnesses and court consultants in legal cases related to prison conditions of confinement. These relationships have included the American Civil Liberties Union, Squire Patton Boggs, the Center for Constitutional Rights, the Disability Rights Legal Center, and the University of
Denver Student Law Office. No such relationships played a role in the analysis or preparation of this manuscript.

All other authors declare that they do not have a conflict of interest.

\section{REFERENCES}

1. Drucker E. A Plague of Prisons: The Epidemiology of Mass Incarceration in America. New York: New Press; 2011.

2. Rich JD, Wakeman SE, Dickman SL. Medicine and the epidemic of incarceration in the United States. N Engl J Med. 2011;364(22):2081-3.

3. Dumont DM, Allen SA, Brockmann BW, Alexander NE, Rich JD. Incarceration, community health, and racial disparities. J Health Care Poor Underserved. 2013;24(1):78-88.

4. Peters RH, Wexler HK, Lurigio AJ. Co-Occurring Substance Use and Mental Disorders in the Criminal Justice System: A New Frontier of Clinical Practice and Research. Psychiatric Rehab J. 2015;38(1):1-6.

5. Binswanger IA, Krueger PM, Steiner JF. Prevalence of chronic medical conditions among jail and prison inmates in the USA compared with the general population. J Epidemiol Community Health. 2009;63(11):912-9.

6. Mallik-Kane K, Visher C. Health and Prisoner Reentry: How Physical, Mental, and Substance Abuse Conditions Shape the Process of Reintegration. Washington, DC: Urban Institute; 2008.

7. Western B, Braga AA, Davis J, Sirois C. Stress and Hardship after Prison. Am J Sociol. 2015;120(5):1512-47.

8. Wildeman C, Muller C. Mass imprisonment and inequality in health and family life. Ann Rev Law Soc Sci. 2012;8:11-30.

9. Comfort M. Doing Time Together: Love and Family in the Shadow of the Prison. Chicago, IL: University of Chicago Press; 2008.

10. Greifinger R, ed. Public Health Behind Bars: from Prisons to Communities. New York: Springer; 2007.

11. Cloud D. On Life Support: Public Health in the Age of Mass Incarceration. New York: Vera Institute of Justice; 2014.

12. Ahalt C, Binswanger IA, Steinman M, Tulsky J, Williams BA. Confined to ignorance: the absence of prisoner information from nationally representative health data sets. J Gen Intern Med. 2012;27(2):160-6.

13. Wang EA, Wildeman C. Studying health disparities by including incarcerated and formerly incarcerated individuals. JAMA. 2011;305(16):1708-9.

14. Binswanger IA, Stern MF, Deyo RA, et al. Release from prison-a high risk of death for former inmates. N Engl J Med. 2007;356(2):157-65.

15. Fox AD, Anderson MR, Bartlett G, Valverde J, Starrels JL, Cunningham CO. Health outcomes and retention in care following release from prison for patients of an urban post-incarceration transitions clinic. J Health Care Poor Underserved. 2014;25(3):1139-52.

16. Baillargeon J, Penn JV, Knight K, Harzke AJ, Baillargeon G, Becker EA. Risk of reincarceration among prisoners with co-occurring severe mental illness and substance use disorders. Admin Pol Ment Health. 2010;37(4):367-74.

17. Committee on Causes and Consequences of High Rates of Incarceration Committee on Law and Justice; Division of Behavioral and Social Sciences and Education; National Research Council; Board on the Health of Select Populations; Institute of Medicine. Health and Incarceration: A Workshop Summary. A. Smith, Rapporteur. Washington, DC: National Academies Press; 2013.

18. Ahalt C, Bolano M, Wang EA, Williams B. The state of research funding from the National Institutes of Health for criminal justice health research. Ann Intern Med. 2015;162(5):345-52.

19. Gostin LO. Biomedical research involving prisoners: ethical values and legal regulation. JAMA 2007;297(7):737-40.

20. Institute of Medicine Committee on Ethical Considerations for Revisions to DHHS Regulations for Protection of Prisoners Involved in Research. Gostin LO, Vanchieri C, Pope A, eds. Ethical considerations for research involving prisoners. Washington, DC: National Academies Press; 2006. Available at: https://www.ncbi.nlm.nih.gov/books/NBK19882/. Last accessed 16 May 2017.

21. Hornblum AM. They were cheap and available: prisoners as research subjects in twentieth century America. BMJ. 1997;315(7120):1437-41.

22. Green DH. Ethics governing the service of prisoners as subjects in medical experiments: report of a committee appointed by Governor Dwight H. Green of Illinois. JAMA. 1948;136:457-8. Available at: http://jamanetwork.com/journals/jama/fullarticle/298736. Last accessed 13 Sep 2017.

23. Harkness JM. Nuremberg and the issue of wartime experiments on US prisoners. The Green Committee. JAMA. 1996;276(20):1672-5. 
24. McDermott BE. Coercion in research: are prisoners the only vulnerable population? J Am Acad Psychiatry Law. 2013;41(1):8-13.

25. Paul C, Brookes B. The Rationalization of Unethical Research: Revisionist Accounts of the Tuskegee Syphilis Study and the New Zealand "Unfortunate Experiment". Am J Public Health. 2015;105(10):e12-9.

26. In: Gostin LO, Vanchieri C, Pope A, eds. Ethical Considerations for Research Involving Prisoners. Washington (DC); The National Academies Press. 2007. https://doi.org/10.17226/11692.

27. National Commission for the Protection of Human Subjects of Biomedical and Behavioral Research. Report and Recommendations: Research Involving Prisoners. Bethesda, MD: Department of Health, Education, and Welfare Publication No. (OS) 76-131; 1976. Available at: https:// videocast.nih.gov/pdf/ohrp_research_involving_prisoners.pdf.

28. National Commission for the Protection of Human Subjects of Biomedical and Behavioral Research. The Belmont Report: Ethical Principles and Guidelines for the Protection of Human Subjects of Research. Bethesda, MD: U.S. Department of Health, Education, and Welfare; 1978. Available at: http://www.hhs.gov/ohrp/regulations-and-policy/belmont-report/.

29. Porter JP. The federal policy for the protection of human subjects. IRB Rev Hum Subj Res. 1991;13(5):8-9.

30. Kimmelman J. Valuing risk: the ethical review of clinical trial safety. Kennedy Inst Ethics J. 2004; 14(4):369-93.

31. Siegel JE, Roberts MJ. Reforming FDA Policy Lessons from the AIDS Experience. Regulation (Cato Review of Business \& Government). $1991 ; 14: 71-7$

32. FDA. Expanded Access and Expedited Approval of New Therapies Related to HIV/AIDS. 2009. Available at: http://www.fda.gov/ForPatients/Illness/HIVAIDS/Treatment/ucm134331.htm.

33. Novick A. Civil disobedience in time of AIDS. Hast Cent Rep. 1989; 19(6):35-6.

34. Liu KA, Mager NA. Women's involvement in clinical trials: historical perspective and future implications. Pharm Pract (Granada). 2016;14(1):708.

35. Thomas SB, Quinn SC, Butler J, Fryer CS, Garza MA. Toward a fourth generation of disparities research to achieve health equity. Annu Rev Public Health. 2011;32:399-416.

36. Rhode Island Department of Corrections Research Policy. Policy Number 6.064 DOC, effective 11/3/2014. Available at: http://www.doc.ri.gov/administration/planning/docs/6.06-4\%20RIDOC\%20Research\%20Policy.pdf. Last accessed 14 Sep 2017.

37. Nunn A, Cornwall A, Fu J, Bazerman L, Loewenthal H, Beckwith C. Linking HIV-positive jail inmates to treatment, care, and social services after release: results from a qualitative assessment of the COMPASS Program. J Urban Health. 2010;87(6):954-68.

38. Zaller ND, Holmes L, Dyl AC, et al. Linkage to treatment and supportive services among HIV-positive ex-offenders in Project Bridge. J Health Care Poor Underserved. 2008;19(2):522-31.

39. McKenzie M, Nunn A, Zaller ND, Bazazi AR, Rich JD. Overcoming obstacles to implementing methadone maintenance therapy for prisoners: implications for policy and practice. J Opioid Manag. 2009;5(4):219-27.

40. Rich JD, McKenzie M, Larney S, et al. Methadone continuation versus forced withdrawal on incarceration in a combined US prison and jail: a randomised, open-label trial. Lancet. 2015;386(9991):350-9.

41. Zaller N, McKenzie M, Friedmann PD, Green TC, McGowan S, Rich JD. Initiation of buprenorphine during incarceration and retention in treatment upon release. J Subst Abus Treat. 2013;45(2):222-6.

42. Freyer FJ. R.I. prison takes a leap into comprehensive addiction care. Boston Globe. 2017 Aug 14. Available at: https://www.bostonglobe.com/ metro/2017/08/13/prison-takes-leap-into-comprehensive-addictioncare/K3lxG2FPWsI7mmwqMOSXxN/story.html. Last accessed 14 Sep 2017.

43. California Senate Bill No. 1238. An act to amend sections 3500 and 3502 of the penal code, relating to prisons. Approved by the Governor August 25, 2016. Available at: https://leginfo.legislature.ca.gov/faces/ billTextClient.xhtml?bill_id=201520160SB1238.

44. State of California, Assembly Committee on Appropriations. Analysis of Senate Bill No. 1399 (2009-10 Regular Session), as amended August 2, 2010. Available at: ftp://leginfo.ca.gov/pub/09-10/bill/sen/sb_13511400/sb_1399_cfa_20100803_160918_asm_comm.html.

45. Massachusetts Department of Public Health. An Assessment of Fatal and Nonfatal Opioid Overdoses in Massachusetts (2011-2015). Boston, MA. 2017. Available at: http://www.mass.gov/eohhs/docs/dph/stop-addiction/legislative-report-chapter-55-aug-2017.pdf. Last accessed 5 Dec 2017.

46. Thomas EG, Spittal MJ, Taxman FS, Kinner SA. Health-related factors predict return to custody in a large cohort of ex-prisoners: new approaches to predicting re-incarceration. Health Justice. 2015;3(10).

47. Schittker J, Massoglia M, Uggen C. Incarceration and the health of the African American community. Du Bois Rev. 2011;8(1):133-41.

48. Wagner P, Rabuy B. Mass Incarceration: The Whole Pie 2016. Prison Policy Initiative. Available at: http://www.prisonpolicy.org/reports/ pie2016.html. Accessed 29 Nov 2016. 